\title{
Ensino de Geociências na universidade
}

\author{
UMBERTO G. CORDANI, ${ }^{I}$ \\ MARCIA ERNESTO, ${ }^{I I}$ \\ MARIA ASSUNÇ̃̃O F. DA SILVA DIAS, ${ }^{I I I}$ \\ ELISABETE DE SANTIS B. G. SARAIVA, ${ }^{I V}$ \\ FERNANDO F. DE ALKMIM, ${ }^{V}$ \\ CARLOS ALBERTO MENDONÇA VI \\ ¿ RACHEL ALBRECHT VII
}

\section{Um pouco de história: as Ciências da Terra no Brasil colonial e no Império}

A HISTÓRIA do Brasil colonial compreende duas fases de atividade econômica com base extrativista. A primeira, exclusivamente agrícola e pastoril, se estende pelos dois primeiros séculos após Descobrimento. A segunda, que ficou conhecida como Ciclo do Ouro, tem início em 1698 com as descobertas dos grandes depósitos auríferos de Minas Gerais, e um incremento a partir de 1714, com o início da produção de diamantes, também na região das minas. Marcado por intensa atividade mineira e grande fluxo migratório para o interior do Brasil, o Ciclo do Ouro encerra-se ao final do século XVIII com o esgotamento das lavras a céu aberto e com a falta de tecnologias que permitissem o desenvolvimento de minas subterrâneas. Estima-se que, entre os anos 1700 e 1808, quando da chegada da família real ao Brasil, aproximadamente 700 toneladas de ouro e cerca de três milhões de quilates de diamantes tenham sido extraídos somente em Minas Gerais (Abreu, 1973; Guimarães, 1981; Machado; Figueirôa, 2001 ). Além disso, o afluxo populacional à colônia teria sido de aproximadamente 600.000 portugueses e de 2.600.000 africanos trazidos como escravos.

Apesar da experiência de um século de intensa atividade mineira, o Brasil colonial não foi palco de estudos geocientíficos (ou mesmo científicos de um modo geral) relevantes. Vale mencionar, entretanto, a relação do Brasil com a era das Grandes Navegações, iniciada entre os séculos XV e XVI por portugueses e espanhóis. Portugal, com o estímulo do infante D. Henrique, reunia na Escola de Sagres, considerada o centro de estudos de navegação, cosmógrafos, cartógrafos, mercadores, navegadores e aventureiros. O interesse de Portugal por grandes viagens voltadas ao Atlântico proporcionou aos portugueses a descoberta do Brasil em 1500, por Pedro Álvares Cabral. De certo modo, os 
navegadores se serviam de um conhecimento multidisciplinar sobre circulação atmosférica oceânica, abordados pela oceanografia atual, bem como passaram a cultivar outros interesses, biológicos, químicos e geológicos, os quais complementam a vocação da Oceanografia como um todo, incluindo-a entre uma das sub-áreas das Ciências da Terra. Ademais, os primeiros navegantes portugueses, ao chegarem em terra, registravam a declinação magnética em cada local aportado, dado importante para a navegação mais segura. Os apontamentos por eles feitos constituem, atualmente, fontes de informação preciosas para estudos da variação secular do campo magnético terrestre, podendo-se dizer que, simbolicamente, a geofísica chegou ao Brasil com os seus descobridores. Sobreviveram aos nossos dias alguns poucos documentos do período, todos eles relativos à atividade mineira. Tornou-se muito conhecida a obra do jesuíta italiano Andre João Antonil (1649-1716), intitulada Cultura e opulência do Brasil por suas drogas e minas (Antonil, 1982), publicada em 1711 em Lisboa, que contém uma reportagem sobre as técnicas aqui empregadas na mineração de ouro aluvionar.

Atividades com caráter técnico ou científico bem atribuído têm início no Brasil nos últimos anos do século XVIII com a atuação dos chamados egressos de Coimbra. Brasileiros ilustrados, formados em Coimbra após as reformas pombalinas, engajaram-se em projetos da coroa portuguesa que tinham como objetivo principal revitalizar e ampliar a mineração na colônia, a essa época em franca decadência (Figueirôa et al., 2004; Silva; Figueirôa, 2004). Como representantes destacados desse grupo figuram José Vieira Couto, José Bonifácio de Andrada e Silva e Manoel Ferreira da Câmara Bittencourt Aguiar e Sá.

Vieira Couto (1752-1827), naturalista, nascido no Arraial do Tejuco (hoje Diamantina, MG) e graduado em Coimbra em 1778, produziu quatro monografias: i) Memoria sobre Capitania de Minas Geraes, seu território, clima e producções metallicas, escrita em 1799; ii) Memoria sobre as minas da capitania de Minas Geraes, de 1801; iii) Memoria sobre as nitratreiras naturaes e artificiaes de Monte Rorigo na Capitania de Minas Geraes, escrita em 1803; e iv) Memoria sobre as minas de cobalto de Minas Geraes, de 1805. Além do que vai explicitado nos respectivos títulos, as memórias de Vieira Couto contém descrições pioneiras da geomorfologia e aspectos da geologia de várias partes do território mineiro, além de arrazoados críticos sobre técnicas de mineração então empregadas e propostas de soluções para os problemas existentes (Silva, 2002). Embora não devidamente citadas, é evidente incorporação das observações e críticas de Vieira Couto em textos mais tarde produzidos por outros autores.

Manoel Ferreira da Câmara Bittencourt Aguiar e Sá (1762-1835), nascido provavelmente em Itacambira, Minas Gerais, concluiu o curso na Universidade de Coimbra em 1788, onde foi contemporâneo de José Bonifácio de Andrada e Silva. Após a sua graduação, ingressou na Academia de Ciências de Lisboa, onde publicou em 1789 a monografia Ensaio de Descrição Física e Econômica da Comarca de Ilbéus na América, que foi sucedida, no mesmo, pela Memoria de Observações Físico-Econômicas Acerca da Extração do Ouro do Brasil. Após 
a realização de outros trabalhos, foi aquinhoado com uma bolsa para viagens científicas a vários países europeus, quando faz significativas contribuições aos campos da mineralogia e geognosia (denominação para geologia até meados do século XIX). Retornou ao Brasil em 1808, onde se tornou intendente geral das Minas dos Diamantes do Serro Frio (Varela, 2007). Mais tarde, como deputado da Assembleia Nacional Constituinte de 1823 e senador do Império, reivindicou e atuou para a criação no Brasil de uma escola superior voltada para o ensino de mineração, mineralogia e metalurgia, o que só veio a se concretizar no Brasil ao sinal de século XIX, com a criação da Escola de Minas de Ouro Preto.

José Bonifácio de Andrada e Silva (1763-1838), natural de Santos e que viria a ser mais tarde o patriarca da Independência do Brasil, teve uma destacada carreira como naturalista, notadamente no campo da mineralogia. Como Câmara, após a graduação em Coimbra, em 1790 iniciou viagens pela Europa (Varela et al., 2005) que perduraram por mais de dez anos. Com menos de 40 anos já era plenamente consagrado no mundo da ciência e, em sua estada na França, apresentou em 1792, na Sociedade de História Natural de Paris, um trabalho intitulado Memória sobre os diamantes do Brasil. Depois de concluída a viagem, escreveu em 1800 um artigo científico sobre os minerais novos que encontrou nas minas da Suécia e da Noruega, em que ele fez uma descrição mineralógica e química completa das espécies minerais espodumênio, petalita, criolita e escapolita. Esse trabalho, o primeiro desse nível feito por um brasileiro, foi publicado no mesmo ano na França, na Alemanha e na Inglaterra.

Remontam também ao final do século XVIII outras iniciativas importantes, como a criação em 1780 do Imperial Observatório Nacional (ON) no Rio de Janeiro, a primeira instituição brasileira a se ocupar de estudos geofísicos a partir das instalações montadas por astrônomos portugueses para realizar observações regulares de astronomia e magnetismo terrestre. Segundo Dos Santos (2005), atreladas às observações astronômicas, ocorreram também as primeiras observações meteorológicas documentadas no Brasil.

Com a chegada da corte portuguesa e do príncipe regente Dom João VI em 1808, o Brasil foi aberto aos naturalistas, viajantes e artistas estrangeiros que deixaram importante legado. Inaugura-se então um período de várias investigações científicas do território brasileiro, no qual a grande atuação no ramo das ciências da Terra coube ao alemão Wilhelm Ludwig von Eschwege (17771855), engenheiro militar de profissão, além de naturalista, geólogo, geógrafo e botânico. Foi incumbido pela coroa portuguesa de realizar um estudo do potencial mineiro do país, com a meta de reanimar a decadente mineração de ouro e implementar a nascente indústria siderúrgica. Von Eschwege permaneceu no Brasil até 1821 como intendente das Minas e curador do Real Gabinete de Mineralogia. Além disso, foi encarregado do ensino das ciências da engenharia aos futuros oficiais do exército e do de técnicas avançadas de extração mineral aos mineiros. Considerado pioneiro dos estudos geológicos do Brasil, empreendeu 
várias viagens de exploração geológica, das quais resultou uma vasta contribuição escrita. A sua principal obra, Pluto Brasiliensis (Riqueza do Brasil) (Berlim, 1833), pode ser considerada a primeira peça científica em profundidade e abrangência sobre a geologia do Brasil.

Além de Von Eschwege, muitos novos conhecimentos sobre a história natural do território brasileiro foram obtidos com as expedições realizadas pelos naturalistas viajantes, dentre eles o francês Auguste de Saint Hilaire (1779-1853) e os alemães Karl Friedrich Philipp von Martius (1794-1868) e Johann von Spix (1781-1826), estes últimos autores da famosa monografia Flora Brasiliensis.

Após a Independência, o imperador Dom Pedro II, com seu interesse pelas artes e ciência, empreendeu inúmeros esforços para estabelecimento da pesquisa e ensino das Ciências da Terra no país. Por um tempo, mostrou inclusive preocupação com tremores de terra registrados em vários pontos do Brasil e procurou coletar informações nas províncias. Surge então o que talvez tenha sido a primeira publicação geocientífica feita no Brasil (Capanema, 1859). O próprio imperador foi autor de uma publicação a respeito de um tremor ocorrido em Pernambuco em 1811 (Dom Pedro d'Alcântara, 1860) e posteriormente comunicou outro episódio à mais prestigiada revista científica da época (Dom Pedro d'Alcantara, 1886), os Anais da Academia de Ciências de Paris.

Persistindo no seu intento, D. Pedro II fez, em 1871, uma viagem à França em busca de conselhos para melhor aproveitar o potencial mineral do Brasil. Muito importantes foram os desdobramentos dessa viagem, pois, tendo partido com o intuito de promover o ensino de Mineralogia, Geologia, Mineração e Metalurgia no país, retornou convicto de que deveria também criar as condições para a confecção da carta geológica do território nacional.

As mesmas sugestões recebidas em Paris foram apresentadas ao imperador pelo geólogo canadense Charles Frederick Hartt (1840-1878), que viajou pelo Brasil em 1870-1871 liderando as expedições Morgan, no litoral nordeste do país e na Amazônia, organizadas pela Universidade norte-americana de Cornell. Pelo potencial científico e mineral que o país apresentava, Hartt convenceu as autoridades brasileiras da importância da elaboração de um mapa geológico do país. Em 1875, Dom Pedro II criou, então, a Comissão Geológica do Império, com ênfase no estudo da Geologia e da Paleontologia e das minas brasileiras. Charles F. Hartt foi o seu primeiro coordenador, cargo que exerceu até a sua morte prematura, em 1878, vítima de um surto de febre amarela. Uma resenha sobre os escritos de Hartt apareceu na edição da revista Nature em 1870, assinada por Alfred Wallace, um dos proponentes da teoria da evolução das espécies junto com Charles Darwin.

Durante a expedição Morgan, um dos principais ajudantes de Charles Hartt foi o geólogo e geógrafo estadunidense Orville Adalbert Derby (18511915), à época estudante da Universidade Cornell. Convidado para fazer parte da Comissão Geológica do Império, Derby organizou as coleções de minera- 
logia e paleontologia da instituição e, a partir de 1886, dirigiu a importante Comissão Geográfica e Geológica de São Paulo e posteriormente o Serviço Geológico e Mineralógico do Brasil. Muito ativo intelectualmente, Derby fez importantes trabalhos básicos nas ciências da Terra em muitas partes do território brasileiro e publicou, até o início do século XX, inúmeras memórias e artigos científicos nas áreas da mineralogia, petrografia, geologia, geografia e paleontologia. Em vista de suas grandes e numerosas contribuições, Orville Derby é considerado o pai da geologia do Brasil. Nessa época, no contexto da Comissão Geográfica e Geológica, e publicação no Quarterly Journal of the Royal Meterorological Society, foram documentados novos registros meteorológicos sobre o território brasileiro (Dos Santos, 2005).

Na mencionada viagem que fez a Paris em 1871, Dom Pedro II viabilizou a contratação do naturalista e geólogo francês Claude Henri Gorceix (18421919) para vir ao Brasil e se incumbir da criação de uma escola superior de mineralogia, geologia, mineração e metalurgia. Após várias viagens de Gorceix pelo Brasil para escolha do local de instalação da escola, foi finalmente fundada a Escola de Minas (EMOP) em 12 de outubro de 1876 em Ouro Preto, então capital da província de Minas Gerais. Nos anos seguintes, a EMOP, que originalmente se organizou segundo o modelo das escolas de montanhística de Freiberg e Saint Etienne, ampliou o seu escopo ao se espelhar na Escola de Minas de Paris. Desde a sua fundação em 1876 até 1960, ano de conclusão da primeira turma de geólogos nos cursos instalados pela Campanha de Formação de Geólogos (CAGE) (ver adiante), graduaram-se pela EMOP 827 engenheiros. Um grande número deles atuou profissionalmente como geólogo, tanto em empresas de mineração e exploração mineral como em órgãos governamentais e instituições de Ensino Superior. Um dos importantes legados do fundador da escola foi a ênfase nos conhecimentos em geociências, praticado por todos os seus sucessores (Alkmim; Menezes, 2008).

\section{As motivações para a criação de cursos de Geologia, Meteorologia, Geofísica e Oceanografia no Brasil}

Em vista da navegação marítima sempre sujeita a intempéries, no final do século XIX e início do século XX, houve grande motivação para o estabelecimento de um serviço meteorológico no Brasil. As tempestades marítimas na costa de Santa Catarina e do Rio de Janeiro impulsionaram a necessidade de um acompanhamento mais detalhado das variáveis meteorológicas, o que, aliás, já ocorria nos países desenvolvidos do Hemisfério Norte. Além da Comissão Geográfica e Geológica, ocupavam-se de meteorologia a Repartição dos Telégrafos, a Repartição Hidrográfica, ligada ao Ministério da Marinha, e o Imperial Observatório Astronômico do Rio de Janeiro. Este último deu lugar em 1909 à Diretoria de Meteorologia e Astronomia, a qual originou o atual Instituto Nacional de Meteorologia (INMET) do Ministério da Agricultura e Pecuária. Barboza (2006) descreve a evolução das redes meteorológicas de observação nessa época 
e o uso do telégrafo para transmissão das informações para previsão do tempo. Nessa época, o Brasil incorporava as teorias científicas desenvolvidas em latitudes médias na Europa e Estados Unidos, referentes à movimentação de massas de ar e frentes frias, e sofria com falhas de previsão devidas, essencialmente, às lacunas nas observações e à falta de conhecimento sobre os processos inerentes à Meteorologia Tropical. O ensino informal da Meteorologia ocorria somente do ponto de vista técnico, através de disciplinas para observadores meteorológicos na Escola Normal da Praça da República (Dos Santos, 2005) e a partir da atuação de formados em outras áreas, seja da geografia, geologia, biologia, agricultura, astronomia ou engenharia.

Com relação à Geologia, em 1907 foi criado o Serviço Geológico e Mineralógico do Brasil, sob a direção de Orville Derby, e até a década de 1930 estava sendo apenas incubada uma cultura geológica nacional. Com a criação de universidades, do Conselho Nacional do Petróleo e da Companhia Vale do Rio Doce, e com todas as mudanças experimentadas pelo setor mineral, gerou-se no Brasil uma crescente demanda de profissionais com formação específica em Geologia. Já no governo de Getulio Vargas, em 1934, uma nova constituição separou as propriedades do solo e do subsolo e nacionalizou as reservas minerais do país. Por essa norma legal foi criado o Departamento Nacional da Produção Mineral (DNPM), como órgão governamental encarregado de planejar, gerir e fiscalizar o exercício das atividades de mineração em todo o território nacional, zelando para que o aproveitamento dos recursos minerais fosse realizado de forma racional e controlada.

Quanto à geofísica, foi instalado pelo Observatório Nacional, em 1915, o Observatório Magnético de Vassouras. Além disso, o ON também realizou as primeiras medidas do campo de gravidade no Brasil, que resultaram nas redes de referência a partir de 1955. Digno de nota também foi o estudo de prospecção magnética realizado por M. C. Malamphy no Estado de Santa Catarina, e publicado em 1936 no primeiro número da revista Geophysics, que tinha sido encomendado pelo Serviço Geológico e Mineralógico do Brasil para identificar estruturas favoráveis à acumulação de petróleo.

A Oceanografia no Brasil nasceu em 1946 com o Instituto Paulista de Oceanografia (IPO), cujo objetivo era dar base científica às atividades de pesca, apoiando a exploração de recursos no litoral paulista. Seu fundador foi o professor Wladimir Besnard, ilustre pesquisador, considerado o pai da Oceanografia no Brasil, que atuava na França e que foi convidado a trabalhar no Brasil pelo governo paulista. De início, ele instalou duas bases de pesquisa nas partes norte e sul do litoral do estado, e iniciou suas pesquisas oceanográficas em trechos do complexo estuarino-lagunar de Cananeia-Iguape, onde no final de 1948 foi construído um laboratório flutuante. No litoral norte, as atividades iniciaram-se em 1949, no Canal de São Sebastião, e em maio de 1950, o IPO realizou a sua primeira expedição em mar aberto, no Oceano Atlântico Sul, indo rumo às ilhas 
de Trindade e Martim Vaz. A Incorporação do IPO à Universidade de São Paulo (USP) como Instituto Oceanográfico ocorreu em 1951, e o professor Besnard foi o seu primeiro diretor. Em 1955, o IOUSP adquiriu o Navio Oceanográfico (N/Oc.) Ungava, o primeiro navio nacional de pesquisa, e no ano de 1964 foi assinado um contrato para construção do novo navio, que se chamaria Wladimir Besnard, no estaleiro norueguês de Bergen. Posteriormente, as expedições desse navio para a península Antártica foram importantes no processo de inclusão do Brasil como membro do Tratado Antártico.

Durante toda a primeira metade do século XX, o contingente de profissionais envolvidos com as ciências da Terra no Brasil não ultrapassava 5-6 dezenas de pessoas, oriundas dos cursos de História Natural ou de Engenharia existentes no Brasil, ou geólogos formados no exterior, que desenvolviam algumas atividades ligadas ao conhecimento do arcabouço geológico do território brasileiro. Em 1949 foi fundada a Sociedade Brasileira de Geologia, com engenheiros, geógrafos ou naturalistas, mas sem geólogos brasileiros. Com as atividades mineiras, e com o início ao sistemático processo de exploração de petróleo e gás, pela criação da Petrobrás, em 1953, tornou-se urgente a formação de pessoal técnico em número e qualidade para o desenvolvimento mineral brasileiro.

Com sua meta de "50 anos em 5", o presidente recém-eleito em 1957, Juscelino Kubitschek, desejava fomentar a indústria nacional, com investimentos na área tecnológica. Em particular, a Geologia era uma das mais deficitárias, e por isso buscou instalar cursos superiores de padrão e qualidade, em regime de tempo integral e dedicação exclusiva, num ambiente integrado de ensino e pesquisa. Foi criada nesse ano a Campanha de Formação de Geólogos (CAGE), que fomentou a criação e forneceu recursos materiais e humanos para quatro cursos de Geologia: em Porto Alegre, São Paulo, Recife (PE) e em Ouro Preto (MG). No ano seguinte foram criados dois outros cursos, em Salvador e Rio de Janeiro. Alguns anos depois, com a primeira leva de bacharéis formados nos cursos de Geologia, a profissão de geólogo veio a ser regulamentada, ficando reservada exclusivamente aos graduados em Geologia, sob a fiscalização do Conselho de Engenharia e Arquitetura.

No caso da Geofísica, a Petrobras havia iniciado de forma regular, nos anos 1960, o reconhecimento aerogeofísico das bacias sedimentares, e o levantamento gravimétrico dessas bacias, visando a delimitação de estruturas geológicas para prospecção de petróleo. As atividades crescentes ligadas à exploração de petróleo levaram a empresa a criar cursos e atividades de capacitação profissional de físicos, engenheiros, geólogos, entre outros, para formar especialistas em tópicos diversos dos métodos exploração, com implementação de base computacional para processamento de dados e interpretação de dados sísmicos e de geofísica de poço. Alguns anos mais tarde, as muitas ações de cunho mais científico e observacional em algumas universidades que haviam iniciado estudos geofísicos e geodésicos, do Observatório Nacional, que havia criado em 
1915 o Observatório de Vassouras, do IBGE que havia expandido a cobertura de dados gravimétricos, e do DNPM com atividades de geofísica aplicada, levaram à criação de cursos formais de geofísica, mas em nível de pós-graduação. $\mathrm{Na}$ época algum ensino já ocorria nas universidades, pela oferta de disciplinas versando sobre alguns tópicos da Geofísica em cursos de graduação em Física, Geologia e outros. Entretanto, a formação de profissionais somente teria início com os cursos de pós-graduação criados na Universidade Federal da Bahia (1969), na Universidade de São Paulo (1972) e na Universidade Federal do Pará (1973). De modo geral, esses cursos nasceram de grupos de ciências exatas, porém com inspirações diferentes, uma com vocação para tópicos aplicados, de interesse imediato para setores industriais, outra vertente para estudos globais e de conhecimento básico. Em 1978 foi fundada a Sociedade Brasileira de Geofísica (SBGf), pois os geofísicos até então não contavam com um fórum único para se reunir. A SBGf, desde então, organizou seu Congresso Internacional de Geofísica e, a partir de 2004, o Simpósio Brasileiro de Geofísica. Finalmente, a necessidade de contar com um ensino iniciado diretamente em Geofisica, a partir de jovens egressos do Ensino Médio, em regime de tempo integral durante 4-5 anos, levou à criação dos cursos de graduação. O primeiro ocorreu na USP em 1983 e o segundo na Universidade Federal da Bahia (UFBa), em 1992.

\section{Características dos cursos de graduação em Geociências}

A Tabela 1 apresenta a relação das 47 universidades brasileiras, federais, estaduais e privadas, que ofereceram em 2018 cursos de graduação nas Ciências da Terra, com as respectivas datas de início. Verifica-se que há 33 cursos de Geologia, além de três de Engenharia Geológica, 14 cursos de Meteorologia, 13 de Oceanografia e 8 de Geofísica. A criação desses cursos ao longo das últimas seis décadas obedeceu a diferentes circunstâncias, tais como inaugurar algumas áreas científicas específicas ou atender a pressões do mercado profissional em desenvolvimento.

\section{Cursos de Geologia}

Com relação à geologia, como já foi exposto, os primeiros seis cursos foram iniciados no fim da década de 1950, contando com a estrutura das universidades que os receberam e com recursos financeiros fornecidos pela Campanha de Formação de Geólogos (CAGE). A maioria de seus professores já fazia parte das universidades brasileiras, mas com o auxílio da CAGE foram contratados muitos profissionais estrangeiros, em especial diversos geólogos que pertenciam ao Serviço Geológico dos Estados Unidos (USGS), que já se encontravam no Brasil, num acordo com o governo brasileiro, para o projeto de avaliação dos recursos minerais do Quadrilátero Ferrífero. Max White, Norman Herz, Patrick Delaney, entre outros, em muito contribuíram para o desenvolvimento da geologia no Brasil na década de 1960

Os cursos iniciais de Geologia tinham duração de quatro anos e a maioria dos egressos, em 1960 e 1961, foi absorvida nas atividades de prospecção mi- 
Tabela 1 - Universidades brasileiras nas Ciências da Terra

\begin{tabular}{|c|c|c|c|c|c|c|}
\hline Instituição & Localização & Manutenção & Geologia & Geofísica & Meteorologia & Ocenografia \\
\hline $\begin{array}{l}\text { Centro Universitário de Belo } \\
\text { Horizonte - UniBH }\end{array}$ & $\begin{array}{c}\text { Belo Horizon- } \\
\text { te, MG }\end{array}$ & Particular & 2014 & & & \\
\hline $\begin{array}{l}\text { Faculdade do Noroeste de } \\
\text { Minas - FINOM }\end{array}$ & $\begin{array}{l}\text { Patos de } \\
\text { Minas. MG }\end{array}$ & Particular & 2013 & & & \\
\hline $\begin{array}{l}\text { Universidade da Amazônia - } \\
\text { UNAMA }\end{array}$ & Belém, PA & Particular & 2015 & & & \\
\hline Universidade de Brasilia - UNB & Brasilia, DF & Federal & 1965 & 2009 & & \\
\hline $\begin{array}{l}\text { Universidade de São Paulo } \\
\text { - USP }\end{array}$ & São Paulo, SP & Estadual & 1957 & 1983 & 1976 & 2002 \\
\hline $\begin{array}{l}\text { Universidade do Estado do } \\
\text { Amazonas - UEA }\end{array}$ & Manaus, AM & Estadual & & & 2008 & \\
\hline $\begin{array}{l}\text { Universidade do Estado do Rio } \\
\text { de Janeiro - UERJ }\end{array}$ & $\begin{array}{c}\text { Rio de Janei- } \\
\text { ro, RJ }\end{array}$ & Estadual & 1977 & & & 1977 \\
\hline $\begin{array}{l}\text { Universidade do Estadual Pau- } \\
\text { lista - UNESP }\end{array}$ & Bauru, SP & Estadual & & & 2014 & \\
\hline $\begin{array}{l}\text { Universidade do Norte Flumi- } \\
\text { nense - UENF }\end{array}$ & Macaé & Estadual & & & 2013 & \\
\hline $\begin{array}{l}\text { Universidade do Rio dos Sinos } \\
\text { - UNISINOS }\end{array}$ & \begin{tabular}{|c|} 
São Leopoldo, \\
RS
\end{tabular} & Particular & 1973 & & & \\
\hline $\begin{array}{l}\text { Universidade do Rio Grande do } \\
\text { Sul - UFRGS }\end{array}$ & \begin{tabular}{|c|} 
Porto Alegre, \\
RS
\end{tabular} & Federal & 1957 & & & \\
\hline $\begin{array}{l}\text { Universidade Estadual de Cam- } \\
\text { pinas - UNICAMP }\end{array}$ & Campinas, SP & Estadual & 1998 & & & \\
\hline $\begin{array}{l}\text { Universidade Estadual Paulista } \\
\text { - UNESP }\end{array}$ & Rio Claro, SP & Estadual & 1969 & & & \\
\hline $\begin{array}{l}\text { Universidade Federal da Bahia } \\
\text { - UFBa }\end{array}$ & Salvador, Ba & Federal & 1958 & 1992 & & 2003 \\
\hline $\begin{array}{l}\text { Universidade Federal de Alago- } \\
\text { as - UFAL }\end{array}$ & Maceió, AL & Federal & & & 1979 & \\
\hline $\begin{array}{l}\text { Universidade Federal de Cam- } \\
\text { pina Grande - UFCG }\end{array}$ & $\begin{array}{c}\text { Campina } \\
\text { Grande, PB }\end{array}$ & Federal & & & 1973 & \\
\hline $\begin{array}{l}\text { Universidade Federal de Goiás } \\
\text { - UFG }\end{array}$ & Goiânia, GO & Federal & 2015 & & & \\
\hline $\begin{array}{l}\text { Universidade Federal de Itajubá } \\
\text { - UNIFEI }\end{array}$ & Itajubá, MG & Federal & & & 2010 & \\
\hline $\begin{array}{l}\text { Universidade Federal de Mato } \\
\text { Grosso - UFMT }\end{array}$ & Cuiabá, MT & Federal & 1976 & & & \\
\hline $\begin{array}{l}\text { Universidade Federal de Minas } \\
\text { Gerais - UFMG }\end{array}$ & $\begin{array}{c}\text { Belo Horizon- } \\
\text { te, MG }\end{array}$ & Federal & 1973 & & & \\
\hline $\begin{array}{l}\text { Universidade Federal de Ouro } \\
\text { Preto - UFOP }\end{array}$ & $\begin{array}{l}\text { Ouro Preto, } \\
\text { MG }\end{array}$ & Federal & 1957 & & & \\
\hline $\begin{array}{l}\text { Universidade Federal de Pelo- } \\
\text { tas - UFPel }\end{array}$ & Pelotas, RS & Federal & 2008 & & 1978 & \\
\hline $\begin{array}{l}\text { Universidade Federal de Per- } \\
\text { nambuco - UFPe }\end{array}$ & Recife, PE & Federal & 1957 & & & 2009 \\
\hline $\begin{array}{l}\text { Universidade Federal de Rorai- } \\
\text { ma - UFRR }\end{array}$ & Boa Vista, RR & Federal & 2007 & & & \\
\hline $\begin{array}{l}\text { Universidade Federal de Santa } \\
\text { Catarina - UFSC }\end{array}$ & \begin{tabular}{|c|} 
Florianópolis, \\
SC
\end{tabular} & Federal & 2009 & & 2012 & 1998 \\
\hline
\end{tabular}




\begin{tabular}{|c|c|c|c|c|c|c|}
\hline \multicolumn{7}{|l|}{ Continua } \\
\hline $\begin{array}{l}\text { Universidade Federal de Santa } \\
\text { Maria - UFSM }\end{array}$ & \begin{tabular}{|c|} 
Santa Maria, \\
RS
\end{tabular} & Federal & & & 2005 & \\
\hline $\begin{array}{l}\text { Universidade Federal de Sergi- } \\
\text { pe - UFS }\end{array}$ & Aracaju, SE & Federal & 2007 & & & \\
\hline $\begin{array}{l}\text { Universidade Federal de Uber- } \\
\text { lândia - UFU }\end{array}$ & $\begin{array}{l}\text { Uberlândia, } \\
\text { MG }\end{array}$ & Federal & 2015 & & & \\
\hline $\begin{array}{l}\text { Universidade Federal do Ama- } \\
\text { zonas - UFAM }\end{array}$ & Manaus, AM & Federal & 1976 & & & \\
\hline $\begin{array}{l}\text { Universidade Federal do Ceará, } \\
\text { UFC }\end{array}$ & $\begin{array}{l}\text { Fortaleza, } \\
\text { Ce }\end{array}$ & Federal & 1970 & & & 2007 \\
\hline $\begin{array}{l}\text { Universidade Federal do Espíri- } \\
\text { to Santo - UFES }\end{array}$ & Alegre, ES & Federal & 2005 & & & 2000 \\
\hline $\begin{array}{l}\text { Universidade Federal do Oeste } \\
\text { da Bahia - UFOB }\end{array}$ & Barreiras, BA & Federal & 2006 & & & \\
\hline $\begin{array}{l}\text { Universidade Federal do Oeste } \\
\text { do Pará - UFOPA }\end{array}$ & $\begin{array}{c}\text { Itaituba/San- } \\
\text { tarém, PA }\end{array}$ & Federal & 2015 & 2009 & 2014 & \\
\hline $\begin{array}{l}\text { Universidade Federal do Pam- } \\
\text { pa - UNIPAMPA }\end{array}$ & Bagé, RS & Federal & 2011 & 2006 & & \\
\hline $\begin{array}{l}\text { Universidade Federal do Pará } \\
\text { - UFPa }\end{array}$ & Belém, Pa & Federal & 1964 & 2002 & 1975 & 2000 \\
\hline $\begin{array}{l}\text { Universidade Federal do Para- } \\
\text { ná - UFPr }\end{array}$ & Curitiba, PR & Federal & 1973 & & & 2000 \\
\hline $\begin{array}{l}\text { Universidade Federal do Rio de } \\
\text { Janeiro - UFRJ }\end{array}$ & $\begin{array}{c}\text { Rio de janei- } \\
\text { ro, RJ }\end{array}$ & Federal & 1958 & & 1963 & \\
\hline $\begin{array}{l}\text { Universidade Federal do Rio } \\
\text { Grande do Norte - UFRN }\end{array}$ & Natal, RN & Federal & 1976 & 2009 & 2015 & \\
\hline $\begin{array}{l}\text { Universidade Federal do Sul e } \\
\text { Sudeste do Pará - UNIFESSPA }\end{array}$ & Marabá, PA & Federal & 2013 & & & \\
\hline $\begin{array}{l}\text { Universidade Federal dos Vales } \\
\text { do Jequitinhonha e Mucuri - } \\
\text { UFVJM }\end{array}$ & $\begin{array}{c}\text { Diamantina, } \\
M G\end{array}$ & Federal & 2014 & & & \\
\hline $\begin{array}{l}\text { Universidade Federal Fluminen- } \\
\text { se - UFF }\end{array}$ & Niterói, RJ & Federal & & 2004 & & \\
\hline $\begin{array}{l}\text { Universidade Federal Rural do } \\
\text { Rio de Janeiro - UFRRJ }\end{array}$ & $\begin{array}{c}\text { Seropédica, } \\
\text { RJ }\end{array}$ & Federal & 1970 & & & \\
\hline $\begin{array}{l}\text { Universidade São Judas - UNI- } \\
\text { MONTE }\end{array}$ & Santos, SP & Particular & & & & $1998^{*}$ \\
\hline Universidade Vila Velha - UVV & $\begin{array}{l}\text { Vila Velha, } \\
\text { ES }\end{array}$ & Particular & 2017 & & & \\
\hline $\begin{array}{l}\text { Universidade do Valo do Itajaí } \\
\text {-UNIVALI }\end{array}$ & Itajaí, SC & Privada & & & & 1992 \\
\hline $\begin{array}{l}\text { Universidade Federal do Rio } \\
\text { Grande-FURG }\end{array}$ & \begin{tabular}{|c|} 
Rio Grande, \\
RS
\end{tabular} & Federal & & & & 1971 \\
\hline $\begin{array}{l}\text { Universidade Federal do Mara- } \\
\text { nhão -UFMA }\end{array}$ & $\begin{array}{l}\text { São Luiís, } \\
\text { MA }\end{array}$ & Federal & & & & 2006 \\
\hline
\end{tabular}


neral e de petróleo. Nos 20 anos seguintes foram instalados mais 12 cursos de Geologia (Tabela 1), em virtude do crescimento da demanda de geólogos por causa do aumento nas atividades de exploração mineral e das novas atuações dos profissionais em geologia para o aproveitamento de águas subterrâneas e para a geologia de engenharia, esta última desenvolvida para auxiliar nas grandes obras de engenharia civil que estavam sendo instaladas no Brasil. A partir de 1970, os cursos de Geologia passaram a ter cinco anos, de modo similar aos cursos de Engenharia.

Já nos primeiros anos do século XXI, em grande parte devido à revelação pela Petrobrás do grande potencial petrolífero nas estruturas pré-sal nas bacias da margem leste brasileira, e ao crescimento da demanda de "commodities" em sua primeira década, mais 17 novos cursos de Geologia foram criados muitos deles num passado muito recente (Tabela 1).

Em vistas das transformações tecnológicas e culturais que ocorreram no mundo, a partir da década de 1980 os geólogos foram chamados para atividades relacionadas com conservação e reabilitação ambiental. À geologia foi conferido um papel de importância crescente em todas as questões relacionadas a um melhor entendimento da Terra, no caminho para uma sociedade sustentável. Seu papel é considerado essencial na gestão de recursos minerais e energéticos, gestão de aquíferos, combate à degradação e erosão de solos, e também na mitigação de desastres naturais de causa geológica. Além disso, a geologia voltou-se progressivamente para questões globais, holísticas, inerentes a um "Sistema Ter$r a ”$ e com isto tornou-se mais quantitativa, utilizando largamente a matemática, a estatística e a tecnologia da informação no monitoramento e modelamento dos processos inerentes ao funcionamento e à evolução do planeta.

Essas transformações na sociedade podem ser vistas nas modificações no conteúdo programático dos cursos de Geologia no Brasil. Se em seu início os cursos de Geologia tinham forte ligação com as ciências naturais, e certo viés para atender a busca de recursos minerais e energéticos, com o tempo seu conteúdo se tornou muito mais diversificado, mais quantitativo e mais voltado para opções profissionais, sem porem perder as variantes mais acadêmicas, voltadas para mineralogia, petrologia, paleontologia etc. Com seis décadas de atuação dos cursos de Geologia, estima-se que se formaram, no país, cerca de 30 mil geólogos, dois terços dos quais ainda se encontram ativos. Algumas centenas fazem parte do Serviço Geológico Brasileiro (CPRM) e outros tantos integram as duas principais empresas do país, a Petrobrás e a Vale. Muitos atuam em empresas de serviços, e outros como consultores para exploração mineral, recursos hídricos ou geologia ambiental.

Presentemente, os currículos dos cursos de Geologia no Brasil possuem certa uniformidade, incluindo genericamente: (1) Disciplinas básicas tais como Cálculo, Estatística, Computação, Física, Química, Biologia, e noções holísticas relacionadas com o "Sistema Terra"; (2) Disciplinas específicas com conteúdo 
geológico, tais como Geologia Geral, Mineralogia, Paleontologia, Estratigrafia, Mapeamento Geológico; (3) Disciplinas profissionalizantes, tais como Exploração Mineral, Geologia do Petróleo, Hidrogeologia, Geologia de Engenharia, Geologia Ambiental; (4) Disciplinas optativas diversificadas, muitas delas fora da Geologia; e (5) Normalmente os cursos incluem também um trabalho final de graduação.

\section{Cursos de Meteorologia}

O ensino específico de graduação em Meteorologia se iniciou no Brasil em 1963 na Universidade Federal do Rio de Janeiro (UFRJ). Vários professores indicados pela Organização Meteorológica Mundial (OMM) foram ao Rio de Janeiro para formar as primeiras turmas de meteorologistas, e dessas primeiras turmas foram escolhidos os primeiros docentes brasileiros da Meteorologia na UFRJ. Em 1968 teve inicio a pós-graduação em Meteorologia no Instituto Nacional de Pesquisas Espaciais (Inpe), no contexto do Programa Espacial Brasileiro. Na década de 1970, os graduados da UFRJ e os mestres e doutores formados no Inpe promoveram a expansão dos cursos de graduação em Meteorologia na Universidade Federal de Campina Grande, Paraíba, em 1973; Universidade Federal do Pará, em Belém, Pará, em 1975; Universidade Federal de Pelotas (UFPEL), no Rio Grande do Sul, em 1978; e Universidade Federal de Alagoas (Ufal), em Maceió, em 1979 (Tabela 1). Em São Paulo, a iniciativa de criação de um curso de Meteorologia em 1976 foi independente das demais, com contratação de professores estrangeiros e o envio de docentes para obtenção do doutorado no exterior.

Nas décadas de 1980 e 1990, o número de cursos de graduação em Meteorologia permaneceu estável. A partir de 2005 e até 2014, o total de cursos passou por nova expansão e chegou ao número de 13. Razões para essa expansão são diversas, mas é interessante notar que o mercado de trabalho e as instituições de pesquisa também se expandiram e se diversificaram nessa mesma época. As áreas de aplicação da Meteorologia passaram a demandar projetos e profissionais da área. Em particular, os setores de energia hidroelétrica, eólica e solar e a área de poluição do ar contrataram profissionais da meteorologia em todas as regiões do país. A conscientização sobre o papel da meteorologia de precisão na agricultura impulsionou novas áreas de aplicação. Programas do Ministério da Ciência e Tecnologia promoveram a implantação do Centro de Previsão de Tempo e Estudos Climáticos (CPTEC) no Inpe, em 1994, e nos anos seguintes de núcleos de meteorologia nos estados voltados aos problemas regionais. A expansão relativamente desordenada da meteorologia no país provocou alguns conflitos, como na atuação dos grupos mais tradicionais como o INMET, a Diretoria de Hidrografia e Navegação (DHN) do Ministério da Marinha e o Departamento de Controle do Espaço Aéreo (Decea) do Ministério da Defesa, com o novo ator representado pelo CPTEC/Inpe. Nos estados de Rio de Janeiro e São Paulo, diversos órgãos surgiram com sobreposição de atuação. Apesar da evidente 
duplicação de esforços, que causou certo desperdício de recursos financeiros, a expansão certamente contribuiu para a consolidação do mercado de trabalho e abriu espaço também para a iniciativa privada com o estabelecimento de várias empresas de serviços de meteorologia.

Os cursos de Meteorologia no Brasil são estruturados em forte fundamentação matemática (Cálculo, Álgebra, Vetores e Geometria, Estatística e Computação) e física (teóricas e laboratórios), e também conceitos fundamentais de meteorologia (e.g., instrumentos meteorológicos, termodinâmica da atmosfera, radiação solar e terrestre, climatologia, meteorologia sinótica e física). Destaca-se também a sólida formação em conceitos avançados na maioria dos cursos, como meteorologia tropical, dinâmica atmosférica, micrometeorologia, hidrometeorologia, agrometeorologia, radares meteorológicos e sensoriamento remoto por satélites. Os cursos também exigem estágio curricular obrigatório e trabalho de conclusão de curso, seguindo as diretrizes do MEC para bacharelado em Meteorologia e Ciências Atmosféricas.

\section{Cursos de Geofísica}

Como já mencionado, os primeiros cursos formais de geofísica foram criados em nível de pós-graduação, pelo interesse científico de pessoal existente nas universidades de São Paulo, Bahia e Pará, com formação em física ou geologia. Nos anos 1960, por recomendação da Unesco, foi iniciada a instalação de uma rede sismológica na recém-criada Universidade de Brasília, para compor o arranjo sismográfico de alta sensibilidade destinado à monitoração da atividade sísmica andina. Na época, no Inpe, no estado de São Paulo, havia também uma importante área de pesquisa em Geofísica Espacial, que desde então se estabeleceu, e trata de observações geomagnéticas e das interações Sol-Terra. Ademais, na década de 1970, para realizar um primeiro reconhecimento de parâmetros geofísicos, em escala continental, já estavam sendo efetuados, no território brasileiro, levantamentos regionais pelo Observatório Nacional do ON, em parceria com a USP e a UFPr, visando a implantação de uma Rede Gravimétrica de Referência para a representação e interpretação do campo de gravidade no Brasil.

Ao mesmo tempo, em vista do aumento das atividades de exploração mineral no Brasil, levantamentos regionais de geofísica foram realizados pela Companhia de Pesquisa de Recursos Minerais (CPRM) em muitas áreas com potencial mineral, e o Departamento Nacional de Produção Mineral (DNPM) coordenou o reconhecimento aerogeofísico do escudo cristalino. Nesse último aspecto, os dados obtidos na vasta região Amazônica forneceram uma base de dados fundamental para o conhecimento geológico dessa área até então desconhecida do território brasileiro. Além disso, em face da demanda mundial por minério de ferro, abundante no Brasil, as províncias do Quadrilátero Ferrífero de Minas Gerais, e da Serra dos Carajás do estado do Paraná, ambas com relevância mundial, foram cobertas por levantamentos de gravimetria aerotransportada por empresas públicas e privadas. São dessa época também os levantamen- 
tos radioativos efetuados pela Comissão Nacional de Energia Nuclear (CNEN) e pela Nuclebras para a prospecção de jazidas de Urânio, e os muitos estudos com geofísica terrestre, realizados pela CVRD (atualmente Vale) para a exploração de recursos minerais não ferrosos.

No caso da exploração de petróleo, a Petrobras deu início à prospecção na plataforma continental nas bacias de Sergipe e de Campos, que levou a descobertas de campos gigantes em águas profundas. A exploração econômica da plataforma continental motivou estudos científicos regionais, desenvolvidos nos projetos Remac (Reconhecimento da Margem Continental) na década de 1970. Posteriormente, já no século presente, foram descobertas as reservas do pré-sal, em águas ultraprofundas, e a exploração de petróleo na plataforma exigiu a cobertura sistemática com sísmica de reflexão, aquecendo o mercado de trabalho e de serviços.

Essas numerosas atividades de geofísica efetuadas por algumas universidades e por algumas instituições científicas, aliadas às ações de geofísica aplicada à exploração mineral e à prospecção de petróleo, realizadas por diversos órgãos governamentais e por empresas privadas, exerceu a pressão necessária para a criação de cursos de graduação, em tempo integral, que pudessem atender à demanda de pesquisadores e profissionais competentes. Os primeiros cursos de Geofísica instalados no Brasil ocorreram justamente naquelas universidades onde já havia uma pós-graduação consolidada, na USP (1983), UFBa (1992) e UFPa (2002). Os cinco outros cursos de Geofísica no Brasil vieram a ser criados entre 2004 e 2009 (Tabela 1), em razão de uma forte demanda do mercado de trabalho, em vista da aceleração da produção de petróleo pela Petrobras e do grande incremento das atividades de exploração mineral pelo ciclo mundial de maior valor das "commodities minerais".

As grades curriculares do ensino de graduação em Geofisica fornecem forte fundamentação em matemática e física, nos primeiros semestres, o que forma a base para introduzir as metodologias específicas da geofísica aplicada (sísmica, métodos potenciais, métodos elétricos e eletromagnéticos, métodos radiométricos). Alguns cursos, como o da USP, introduzem também disciplinas para a formação mais acadêmica ou de investigação profunda da Terra (geomagnetismo, paleomagnetismo, sismologia, geotermia, dinâmica e evolução da Terra). Os cursos exigem trabalhos de conclusão do curso realizados na própria unidade, junto a outros grupos de geofísica ou em empresas.

\section{Cursos de Oceanografia}

O estudo sistemático da Oceanografia, que teve início no Brasil com a criação do Instituto PauIista de Oceanografia (1946), foi posteriormente absorvido pela Universidade de São Paulo, passando a denominar-se lnstituto Oceanográfico. Em 1954 foi criada a Sociedade de Estudos Oceanográficos do Rio Grande (SEORG) e, em seguida, foi realizada a Semana Oceanográfica e fundado o Museu e Aquário Oceanográfico (1955). Esses acontecimentos impul- 
sionaram as pesquisas e os estudos oceanográficos no Brasil. As demandas em razão do desenvolvimento econômico brasileiro incentivaram a implementação da formação de recursos humanos na pesca, as quais culminaram com a criação do primeiro curso oceanográfico do Brasil, em 1970, na Universidade Federal de Rio Grande (FURG), com a denominação "Curso de Oceanologia", e a sua primeira turma iniciou seus estudos em 1971. Com a dificuldade de se compor um currículo nacional, foram buscadas informações para a sua organização em universidades dos Estados Unidos, da Rússia e da França. Na época a região Sul passava por uma importante projeção nacional, fortemente influenciada pela criação da Superintendência de Desenvolvimento Pesqueiro (Sudepe), em 1962. O curso de Oceanologia em Rio Grande, junto à Lagoa dos Patos e com acesso ao Atlântico Sul, recebeu impulso pela consolidação da indústria pesqueira, bem como pelas condições favoráveis de matéria-prima abundante e mão de obra qualificada para captura e processamento de pescado. A delimitação do mar territorial brasileiro para 200 milhas náuticas, no início de 1970, restringiu a atuação da pesca às águas territoriais, levando a um declínio na indústria pesqueira. Apesar disso, o curso de Oceanologia de Rio Grande se manteve ativo e muito bem estruturado, estando entre os melhores do país. A Associação Brasileira de Oceanografia foi formada em 1975 (AOCEANO, 2009).

A primeira turma da Faculdade de Oceanografia da UERJ teve início em 1977. O curso foi originado como um departamento da universidade, tendo alcançando independência administrativa apenas no final do ano de 2007. O Instituto Oceanográfico da USP foi criado em 1973 com um perfil diferente, e começou a oferecer disciplinas optativas de graduação, recebendo alunos de outras unidades como um complemento do ensino de áreas como a Biologia, a Física, Química e Geologia.

Com o aumento do interesse pela formação em Oceanografia no país, que já ocorria pela demanda existente nos cursos pioneiros, e com a identificação da vocação por diversas universidades do país, sobretudo aquelas localizadas junto às cidades costeiras, apareceram novas ofertas de cursos de especialização. Os mestres e doutores já titulados em Rio Grande, São Paulo e Rio de Janeiro, os professores estrangeiros contratados, e os docentes cativos de várias instituições brasileiras exerceram um papel importante na implantação de novos cursos. Atendendo ao interesse do país para a formação de bacharéis, a Universidade do Vale do Itajaí (Univali) criou o seu bacharelado em 1992, enquanto, em 1998, foram iniciados os bacharelados da Universidade Federal de Santa Catarina (UFSC) e o curso de Oceanografia da Universidade Unimonte, hoje incorporado à Universidade São Judas. Na USP, a criação do curso de Bacharelado em Oceanografia se deu em 2001, com ingresso da primeira turma em 2002.

Com a demanda estabelecida, também devido a questões ambientais globais, firmou-se a necessidade de profissionais para atuar ao longo de uma costa 
litorânea de cerca de $7.400 \mathrm{~km}$ de extensão, com seus domínios contíguos, com espalhamento mar adentro para a chamada "Amazônia Azul", e também além dos limites de águas sob a soberania nacional, visto que a Oceanografia é uma ciência sem fronteira. Com isso, como pode ser visto pela Tabela 1, os cursos de Oceanografia disseminaram-se pelo litoral brasileiro, sendo $11 \mathrm{em}$ universidades públicas e 2, em particulares. Pelas suas características regionais, as disciplinas que compõem as suas estruturas curriculares apresentam importantes diferenças. De um modo geral, as de Matemática (Cálculo e Estatística) compõem a parte básica, e as disciplinas específicas são reunidas em conjuntos que agrupam os conteúdos de Oceanografia Biológica, Física, Química e Geológica. A parte prática inclui embarques (120-150 horas) e por vezes estágios a bordo, e normalmente também é exigido um trabalho de término de curso.

Os oceanógrafos encontram campo de atuação em universidades e em centros de pesquisa. Além disso, atuam junto ao setor público em órgãos federais, estaduais e municipais como secretarias de Meio Ambiente, secretarias de Agricultura e Pesca; secretarias de Obras e de Saneamento e em diversas divisões do Ministério da Marinha. No setor privado, atuam em cooperativas de produtores, setores de segurança e meio ambiente de indústrias químicas e gestão ambiental de portos, indústrias do setor de controle de efluentes e da poluição ambiental, empresas de consultoria ambiental, empresas de engenharia ligada à zona costeira, empresas de extensão pesqueira e aquícola, bem como empresas de exploração, produção e distribuição de petróleo, gás e derivados.

\section{Pesquisa e Ensino de pós-graduação}

As pesquisas geocientíficas integram conhecimentos que são adquiridos por meio da ação de inúmeras especialidades setoriais. O seu principal objetivo é o estudo do Sistema Terra, composto pelo planeta sólido e pelos seus envoltórios fluidos, atmosfera e hidrosfera. Geologia, Geofísica, Meteorologia e Oceanografia buscam explicar como se processa a dinâmica do planeta, ao dissipar tanto a energia interna que o caracteriza, como a energia externa que recebe do Sol, a qual afeta principalmente atmosfera e hidrosfera. Acrescente-se a esses objetivos a função histórica das Geociências, buscando formas de revelar a origem e a evolução da Terra no tempo geológico. Em todas essas áreas setoriais das geociências há muitos exemplos de pesquisas relevantes realizadas por instituições nacionais, que transcendem os aspectos regionais ou locais.

No caso da geologia, as contribuições mais importantes dos pesquisadores brasileiros se dão quando as observações de petrologia, geoquímica de rochas e geoquímica isotópica, bem como de geologia estrutural, são integradas para estudos de geotectônica ou de processos geológicos naturais. Pesquisas paleontológicas e paleoclimáticas efetuadas com rochas e fósseis brasileiros têm sido importantes como contribuição para o conhecimento da evolução biológica e para a evolução climática do planeta durante o tempo geológico. Para a geofísica, os assuntos mais relevantes são os que tratam do material do interior da Terra, em 
suas propriedades sismológicas, gravimétricas e magnéticas, entre outras, para caracterizar os diferentes aspectos de tectônica crustal, do regime de tectônica de placas e a dinâmica do manto, para saber como funciona o planeta.

Por outro lado, presentemente, a participação brasileira na ciência mundial como um todo, e em particular nas Ciências da Terra, possui certo destaque na investigação da dinâmica da Atmosfera e da Hidrosfera. Em vista das dimensões continentais do território brasileiro, e de sua grande extensão ao longo do Atlântico, as Ciências Atmosféricas e Oceanográficas são de grande relevância global, para o planeta, em vista das ameaças à humanidade representadas pelas mudanças climáticas e o aquecimento global. Ademais, deve-se ressaltar que muitas dessas ações científicas foram realizadas na forma de redes de pesquisa internacionais e, neste particular, os estudos de oceanografia no Atlântico Sul e os de mudanças climáticas, que envolvem a região amazônica, têm servido como laboratório para modelagens globais de alto impacto. O grau de internacionalização dessas pesquisas pode ser medido pela expressiva participação de pesquisadores brasileiros em projetos internacionais ligados ao World Climate Research Programme (WCRP), ou ao Scientific Committee on Antarctic Research (SCAR), entre outros.

Deve ser lembrado que as Geociências no Brasil são muito jovens, tendo começado de forma institucional praticamente na segunda metade do século XX. A formação de geólogos no Brasil se iniciou apenas em 1957, e a de geofísicos, meteorologistas e oceanógrafos é posterior. Em vista disso, o conhecimento geocientífico de seu enorme território se encontra ainda bastante incompleto, e o maior desafio dos cientistas e profissionais que atuam na área é justamente o de melhorar o conhecimento existente na escala local ou regional. Dessa forma, a atuação das instituições geológicas e geofísicas, que de um modo geral possuem capacitação científica instalada adequada, buscam feições específicas que ocorrem em certos locais de interesse, e caracterizar processos que atuam sobre rochas, estruturas geológicas e geofísicas etc. no plano regional, com conclusões voltadas para alguma característica particular considerada de interesse. Disso decorre que os estudos de pesquisadores relacionados com Atmosfera ou Hidrosfera apresentam grande interesse internacional, enquanto que aqueles relacionados com a Terra sólida, que sem dúvida são em si meritórios, possuem menor relevância global e pouco aparecem entre o que está sendo produzido como ciência de impacto no mundo.

De acordo com o documento da área de Geociências da Capes (1916), ela compreende, atualmente, 57 programas de pós-graduação. Esse patamar teve um crescimento lento ao longo do tempo, considerando-se os últimos vinte anos, embora tenha experimentado um incremento maior nos últimos cinco anos. Os primeiros programas remontam à década de 1970 e, passados mais de 50 anos do início das atividades refletem o grau de consolidação e maturidade atingido pela área. Vinte e nove programas se referem às Ciências Geológicas, 
11, às Ciências Atmosféricas, 10, às Ciências Geofísicas e Geodésicas, e 6, às Ciências Oceanográficas. A maioria faz parte de instituições públicas de Ensino Superior que também possuem programas análogos de graduação, sendo apenas três programas vinculados a IES de natureza não pública.

A distribuição dos programas de pós-graduação no território brasileiro guarda estreita relação com os indicadores demográficos e de atividade econômica no país, e nesse particular torna-se nítida a assimetria regional existente, visto que cerca de dois terços dos programas se localiza nas partes sudeste e sul, do país, que corresponde a pouco mais de um terço do território. Do total de programas em funcionamento, 42 oferecem cursos de mestrado e doutorado e 15 , somente de mestrado, dois dos quais de mestrado profissional.

Conforme o relatório de avaliação da Capes para a área de Geociências (2017), 55 programas foram avaliados em 2017, com especial ênfase no enquadramento dos docentes permanentes e colaboradores, na certificação da produção intelectual e na participação discente nessa produção. Na avaliação preliminar 14 programas tiveram nota 3, 20 tiveram nota 4 , e 21 conseguiram nota 5 . De acordo com os critérios da Capes, na última etapa da avaliação, os programas mais bem classificados (aqueles com nota 5) foram analisados em detalhe e comparados no tocante ao seu grau de internacionalização, atribuindo-se, quando fosse o caso, notas 6 e 7, respeitando o pressuposto básico que essas notas deveriam contemplar padrões de excelência internacional observados nas diferentes subáreas do conhecimento. Como resultado, oito programas permaneceram com nota 5 , sete alcançaram nota 6 e seis alcançaram nota 7 (ver Tabela 2). Os programas de excelência na área se caracterizam pela consolidação e liderança nacional, como formadores diferenciados de recursos humanos para a pesquisa e pós-graduação. Além disso, tradicionalmente, possuem um elevado patamar de consolidação e internacionalização, o que é registrado pelo intenso intercâmbio com instituições estrangeiras do Hemisfério Norte. Com efeito, no quadriênio 2013-2016, intervalo de tempo que foi avaliado pela Capes, tornou-se evidente o esforço dos programas de pós-graduação em atingir uma melhor visibilidade internacional, pelo aumento significativo de artigos publicados em periódicos internacionais com elevado índice de impacto. Também cresceu o número de livros nacionais de alta qualidade e capítulos de livros publicados por editoras estrangeiras.

A Tabela 2 mostra os 20 programas mais bem avaliados (nota igual ou superior a 5), em que se nota a predominância das instituições de Ensino Superior do sudeste brasileiro, São Paulo, Rio de Janeiro, Minas Gerais e Paraná. Por outro lado, entre os programas considerados de excelência (notas 6 e 7) encontram-se também as universidades federais de Brasília (UNB), Belém (UFPa) e Porto Alegre (UFRGS), além da Fundação Rio Grande (FURG ). Nessa rodada de avaliação da Capes, dos 47 programas existentes, 41 foram considerados positivamente $(80,4 \%)$, enquanto os outros 10 receberam aconse- 
lhamentos no sentido de evoluir para uma melhor situação no futuro. Com 20 programas considerados bons (aqueles com nota 4), oito muito bons (nota 5 ) e 13 considerados de excelência (notas 6 e 7), a situação atual da pós-graduação em Geociências no Brasil indica que a área, em seu conjunto, encontra-se em situação de consolidação e maturidade.

Tabela 2 - Programas de pós-graduação em Geociências mais bem avaliados pela Capes (notas acima de 5 correspondem a "muito bom") em seu relatório de 2017

\begin{tabular}{l|c|c|}
\hline \multicolumn{1}{|c|}{ UFRN } & Geodinâmica e Geofísica & 5 \\
\hline UFRJ & Geociências & 5 \\
\hline ON & Geofísica & 5 \\
\hline UFMG & Geologia & 5 \\
\hline UFOP & Evolução crustal e Recursos Naturais & 5 \\
\hline UNESP/RC & Geociências e Meio Ambiente & 5 \\
\hline UNESP/PP & Ciências Cartográficas & 5 \\
\hline UFPR & Ciências Geodésicas & 5 \\
\hline UFPA & Geologia e Geoquímica & 6 \\
\hline UFF & Geociências (Geoquímica) & 6 \\
\hline INPE & Geofísica Espacial & 6 \\
\hline INPE & Meteorologia & 6 \\
\hline UNICAMP & Geociências & 6 \\
\hline USP & Geofísica & 6 \\
\hline FURG & Gensoriamento Remoto & 7 \\
\hline UNB & Geteorologia & 7 \\
\hline UFRGS & Oceanografia Fisica, Quimica e Geológica & 6 \\
\hline INPE & Geologia & 7 \\
\hline USP & Geociências & 7 \\
\hline USP & Geotectônica & 7 \\
\hline
\end{tabular}

\section{Referências}

ABREU, S.F. Recursos minerais do Brasil, São Paulo: Editora Edgard Blücher, 1973, 734p., v.l e 2.

ALKMIM, F. F.; MENEZES, M. G. O cinquentenário do curso de Geologia nos 131 anos da Escola de Minas de Ouro Preto. Boletim de Geociências da Petrobras, n.16, p.171-194, 2008.

ANTONIL, J. A. A. Cultura e opulência do Brasil por suas drogas e minas. São Paulo: Edusp; Itatiaia, 1982. 157p.

AOCEANO, Guia da Oceanografia. Associação Brasileira de Oceanografia, 2009. Disponível em: <http://www.aoceano.org.br/>. 
BARBOZA, C. H. História da Meteorologia no Brasil - 1997-1917. 2006. Disponível em: <https://www.researchgate.net/publication/265894492_HISTORIA_DA_METEOROLO GIA_NO_BRASIL_1887-1917_A_METEOROLOGIA_TELEGRAFICA>.

CAPANEMA, G. S. Quaes as tradições, ou vestígios geológicos que nos levem à certeza de ter havido terremotos no Brasil. Revista do Instituto Histórico e Geográfico Brasileiro, v.22, p.135-59, 1859.

CAPES. Documento da área de Geociências. 2016.

CAPES. Relatório de Avaliação da área de Geociências. 2017.

CORDANI, U. G. As Ciências da Terra e a Mundialização das Sociedades - IEA-USP. Estudos Avançados, São Paulo, v.9, n.25, p.13-17, 1995.

Geosciences and development: The role of the Earth sciences in a sustainable world. Ciência e Cultura (SBPC), v.50, n.5, p.336-41, 1998.

DOM PEDRO D'ALCÂNTARA. Documentos relativos ao tremor de terra havido em Pernambuco em 1811. Rev. do Instituto Histórico e Geográfico Brasileiro, Rio de Janeiro, v.23, n.401-6, 1860 .

Tremblement de terre survenu au Brésil le 9 mai 1886; Note. Comptes Ren$d u s$, v.102, n.24, p.1351-2, 15 jun.1886.

DOS SANTOS, P. M. Instituto Astronômico e Geofísico da USP - Memórias sobre sua Formação e Evolução. São Paulo: Edusp, 2005. 182p.

FIGUEIRÔA, S. F. M. et al. Aspectos mineralógicos das Viagens Filosóficas pelo território brasileiro na transição do século XVIII para o século XIX. História, Ciências, Saúde. Manguinhos, Rio de Janeiro, v.11, n.3, p.713-29, 2004.

GUimarãeS, J. E. P. História da Mineração no Brasil. São Paulo: Art Editora, 1981. $189 \mathrm{p}$.

MACHADO, I. F.; FIGUEIRÔA, S. F. M. 500 years of mining in Brazil: a brief review. Resources Policy, v.27, p.9-24, 2001.

MALAMPHY, M. C. Magnetic prospecting in Santa Catharina, Brazil. Geophysics, v.1, n.1, p.23-47, 1936.

MOHRIAK, W. U.; TORRES, L. C. Levantamentos geofísicos para delimitação da margem continental brasileira. Revista USP, São Paulo, v.113, n.59-80, 2017.

SILVA, C. P. O desvendar do grande livro da natureza: um estudo da obra do mineralogista José Vieira Couto, 1798-1805. São Paulo; Campinas: Annablume; Fapesp; Unicamp, 2002.

SILVA, C. P.; FIGUEIRÔA, S. F. M. Garimpando ideias. A “Arte de Minerar” no Brasil em quatro memórias na transição tara o século XIX. Revista da $S B H C$, v.2, n.1, p.32$53,2004$.

VARELA, A. G. A trajetória do ilustrado Manuel Ferreira da Câmara em sua "Fase Europeia" (1783-1800). Tempo. Revista do Departamento de História da UFF, v.12, p.165-90, 2007.

VARELA, A. G. et al. Naturalista e Homem Público: a trajetória do ilustrado José Bonifácio de Andrada e Silva em sua fase portuguesa (1780-1819). Anais do Museu Panlista, São Paulo, v.13, n.1, p.207-34, 2005. 
RESUMO - No Brasil colonial, apesar de intensa atividade mineira na busca de ouro e diamantes, não houve práticas geocientíficas relevantes. No século XIX ocorreram diversas explorações geológicas, das quais resultou uma vasta contribuição escrita. Além disso foram criadas importantes instituições, como o Observatório Nacional, o Serviço Meteorológico, o Observatório Magnético de Vassouras e a Escola de Minas de Ouro Preto em 1876. O ensino formal de Geociências no Brasil foi iniciado apenas em 1957, com a Campanha de Formação de Geólogos (CAGE), que criou e forneceu recursos materiais e humanos para quatro cursos de graduação em Geologia. Na Meteorologia a graduação se iniciou em 1963, na Oceanografia em 1971, e na Geofísica em 1983. Atualmente, 47 universidades brasileiras oferecem 71 cursos de graduação nas Geociências. Há 33 cursos de Geologia, três de Engenharia Geológica, 14 de Meteorologia, 13 de Oceanografia e 8 de Geofísica. Há no Brasil 57 programas de pós-graduação em Geociências, 13 dos quais considerados de excelência, indicando que a situação atual da área é de consolidação e maturidade. Geólogos e geofísicos foram absorvidos, em sua maioria, pelas atividades de mapeamento geológico, exploração mineral e de petróleo. Meteorologistas dedicaram-se ao monitoramento meteorológico e climático, e também a projetos de energia hidroelétrica, eólica e solar. Na Oceanografia, os formados atuaram em órgãos relacionados com ambiente, agricultura e no Ministério da Marinha. Quanto à pesquisa, as ciências atmosféricas e oceanográficas são de grande relevância global, no estudo das mudanças climáticas e o aquecimento global. Por sua vez, o maior desafio de geólogos e geofísicos é o de melhorar do conhecimento do território brasileiro, na escala local ou regional.

PALAVRAS-ChAVE: Geologia, Meteorologia, Geofísica, Oceanografia, Ensino de Graduação, Pesquisa em Geociências.

ABSTRACT - In colonial times, in Brazil, although intense mining activities occurred in the search for gold and diamonds, relevant geoscientific actions did not occur. In the $19^{\text {th }}$ century, a few geological exploratory trips were made, from which several written contributions resulted. Moreover, important institutions were created, such as the National Observatory, the Meteorological Service, the Magnetic Observatory at Vassouras and the Mining School of Ouro Preto in 1876, The formal teaching of Geosciences in Brazil started only in 1957, with the "Campaign for the training of geologists" (CAGE), that created and provided material and human resources to four Geology undergraduate courses. In Meteorology the first course was in 1973, in Oceanography in 1971 and in Geophysics in 1983. Now, 48 Brazilian universities offer 71 undergraduate courses in Geosciences, 33 in Geology, 3 in Geological Engineering, 14 in Meteorology, 13 in Oceanography and 8 in Geophysics. Fifty-seven graduate programs exist in Brazil, 13 of which are considered of excellence, indicating that the area is mature and consolidated. Most geologists and geophysicists were absorbed in geological mapping activities, as well as mining and oil exploration. Meteorologists dedicated themselves to meteorological and climatic monitoring, as well as to projects in hydroelectric, wind and solar energy. Graduates in Oceanography worked in institutions related to the environment, agriculture, and to the Ministry of the Navy. The atmospheric and oceanographic sciences are of global relevance in studies of climatic changes and global warming. In turn, the major challenge of geologists and geophysicists is to improve knowledge of the Brazilian territory, at the local and regional scale.

KErWORDs: Geology, Meteorology, Geophyics, Oceanography, Undergraduate teaching, Geoscientific research. 
Umberto G. Cordani é professor do Instituto de Geociências da USP. Foi diretor do Instituto de Estudos Avançados da USP (1994-1997). @- ucordani@usp.br

Marcia Ernesto é professora do Instituto de Astronomia, Geofísica e Ciências Atmosféricas da USP. @-mernesto@usp.br

Maria Assunção F. da Silva Dias é professora do Instituto de Astronomia, Geofísica e Ciências Atmosféricas da USP. @- massuncao.dias@usp.br

Elisabete de Santis B. G. Saraiva é professora do Instituto Oceanográfico da USP.

@ - edsbraga@usp.br

Fernando F. de Alkmim é professor do Instituto de Geociências da Universidade Federal de Ouro Preto. @- ffalkmim@gmail.com

Carlos Alberto Mendonça é professor do Instituto de Astronomia, Geofísica e Ciências Atmosféricas da USP. @-carlos.mendonca@iag.usp.br

Rachel Albrecht é professora do Instituto de Astronomia, Geofísica e Ciências Atmosféricas da USP. @- rachel.albrecht@iag.usp.br

Recebido em 5.9.2018 e aceito em 12.10.2018.

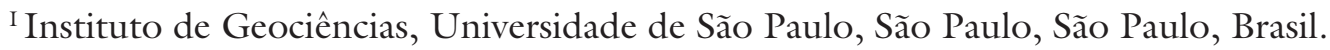

II, III, VI e VII Instituto de Astronomia, Geofísica e Ciências Atmosféricas, Universidade de São Paulo, São Paulo, São Paulo, Brasil.

IV Instituto Oceanográfico, Universidade de São Paulo, São Paulo, São Paulo, Brasil.

v Instituto de Geociências, Universidade Federal de Ouro Preto, Ouro Preto, Minas Gerais, Brasil. 